\title{
La deconstrucción del Estado de bienestar: cambios en el ejercicio profesional de los trabajadores sociales y aumento del voluntariado social
}

\author{
The deconstruction of the welfare State: changes in the practice of social \\ workers and increase in social volunteers
}

\author{
Evaristo BARRERA-ALGARÍN \\ Universidad Pablo de Olavide \\ ebaralg@upo.es \\ José Luis MALAGÓN-BERNAL \\ Universidad Pablo de Olavide de Sevilla \\ jlmalber@upo.es \\ José Luis SARASOlA-SÁNCHEZ-SERRANO \\ Universidad Pablo de Olavide de Sevilla \\ jlsarsan@upo.es
}

Recibido: 26/07/2012

Revisado: 06/11/2012

Aceptado: 15/01/2013

Disponible on line: 16/04/2013

\section{Resumen}

El artículo se sustenta en una vinculación histórica entre la evolución del Estado de bienestar, el desarrollo paralelo del Trabajo Social y del voluntariado social en España. En base a esta relación, cuando el Estado de bienestar entra en un proceso de deconstrucción como el que vivimos y el Trabajo Social sufre una importante adaptación en sus formas y ejercicio profesional. Apoyándose en resultados de reciente investigación sobre los trabajadores sociales andaluces, se obtienen datos que informan sobre cómo ajusta el Trabajo Social incluso sus formas paradigmáticas y metodológicas, y sus condiciones laborales y de contratación. Esta investigación se desarrolla con una metodología cuantitativa-cualitativa, basada en un cuestionario suministrado a una población de 156 trabajadores sociales de la provincia de Sevilla, que a través de la técnica de triangulación, se cruza con los datos obtenidos de los grupos de discusión.

Palabras clave: Trabajo Social, Estado de bienestar, paradigma, metodología, investigación, voluntariado, privatización.

\begin{abstract}
The article is based on a historical connection between the welfare states formation, the parallel development of social work, and the social volunteering evolution in Spain. Based on this relationship, when the welfare states start a deconstruction's process as we can see, the social work suffers a major adaptation in form and practice. Based on evidences from recent research about social workers in the South of Spain (Andalusia), obtained data as social work modifies paradigmatic and methodological forms, and of course their working conditions and hiring. This research was supported by a quantitative-qualitative methodology, based on a sample of 156 social workers in the Seville's Province, and was crossed with data from focus groups in a triangulation technique.
\end{abstract}

Keywords: Social Work, welfare State, paradigm, methodology, research, volunteerism, privatization.

Referencia normalizada: Barrera-Algarín, E., Malagón-Bernal, J. L., y Sarasola-Sánchez-Serrano, J. L. (2013): «La deconstrucción del Estado de bienestar: cambios en el ejercicio profesional de los trabajadores sociales y aumento del voluntariado social». Cuadernos de Trabajo Social, 26(1): 115-126.

Sumario: 1. Nacimiento de los Estados de bienestar, consolidación de la profesión del Trabajo Social, y declive del voluntariado. 2. Deconstrucción del Estado de bienestar. 3. La investigación. 4. Algunos resultados para el debate teórico. 5. Los cambios en el trabajo social. 6. Referencias bibliográficas. 
1. Nacimiento de los Estados de bienestar, consolidación de la profesión del Trabajo Social, y declive del voluntariado

Son evidentes las transformaciones sociales y económicas que se han sucedido desde los denominados «30 años gloriosos» (Castel, 1997; Hamzaoui, 2005) hasta nuestros días. En ellos asistimos a un retroceso del bienestar social, de derechos sociales, trasladándonos a posturas más favorables a los mercados, que a las propias sociedades humanas, y que analizaremos en el apartado siguiente.

Hay un fenómeno asociado que se puede utilizar como indicador de estos cambios, y es precisamente la profesión del Trabajo Social. Esta disciplina va unida al propio desarrollo de los derechos sociales y la inversión en las políticas sociales. El Trabajo Social no se desarrolla en las zonas más pobres, sino en aquellas que, gozando de ciertos niveles de desarrollo y bienestar, invierten en atención social.

Un contexto en el que se puede apreciar de forma clara esta relación entre la evolución del Trabajo Social y el desarrollo del bienestar social, es el modelo español. La época dorada del Trabajo Social ha sido breve y circunscrita a un determinado espacio territorial. Nos estamos refiriendo, evidentemente, al Estado de bienestar y a los pocos países en los que se desarro1ló. El origen inspirador del mismo lo situamos en la obra de Luis Blanc titulada «La organización del trabajo», fundada en Fourier. En ella el autor entabla la relación entre los objetivos políticos y las aspiraciones sociales, que no pueden ser satisfechas más que mediante la intervención del Estado, que tiene además que ser democrático (Droz, 1984, pp. 521-524).

Al comienzo del siglo $\mathrm{XX}$, cuando la industrialización europea empieza a consolidarse, lo hace también el Estado de bienestar, dado que los gobiernos aumentan considerablemente los gastos sociales, buscando como objetivo fundamental la estabilidad política y social. No obstante, el gran desarrollo del Estado de bienestar tiene lugar a partir de la Segunda Guerra Mundial, sobre todo en Europa. Quien lo dota de justificación es Keynes en su obra «Teoría general de la ocupación, el interés y el dinero». La economía keynesiana no trastoca los cimientos de la economía clásica, sino que propone la intervención del Estado en la inversión, que da lugar a un gran aumento de la necesidad de mano de obra y consecuentemente al pleno empleo, piedra angular del Estado de bienestar (Keynes, 1981, p.328).

Esta situación se consolidó en Europa en los años sesenta, y se procura dar respuesta a las demandas sociales de aumentar las prestaciones y que los servicios de bienestar se reconozcan como derechos. Cada país lo desarrolla con sus propios matices, por lo que se empieza a hablar de varios modelos de Estados de bienestar, como hace Esping-Andersen que se refiere a tres regímenes de Estados de bienestar que se corresponden con tres economías políticas (Esping-Andersen, 1993, p. 25). También Norman Johnson hace referencia al pluralismo del bienestar, del que se empieza a hablar a finales de los años setenta (Johnson, 1990, p. 86).

En este proceso histórico podemos observar cómo la acción social privada mengua con el triunfo de los Estados de bienestar en Europa a partir del siglo XX. Con el avance del pensamiento neoliberal, a partir de 1971 cuando el Presidente Nixon decidió finalizar los acuerdos de Bretton Woods, abriendo la espita de la desregulación y poniendo fin al New Deal. La acción social pública comienza un retroceso hasta llegar a nuestros días, y que más adelante abordaremos.

Como ya hemos señalado, a la vez que los Estados de bienestar se consolidan, también lo hace la profesión de Trabajo Social, y los trabajadores sociales, cada vez reciben mayor y mejor preparación en los centros de formación universitarios. El desarrollo de los Estados de bienestar en Europa trajo consigo una serie de mejoras sociales, como fue la incorporación de la mujer al trabajo, la atención a las personas en diversas contingencias - enfermedad, vejez, etc. - y sobre todo el pleno empleo. Junto a estas mejoras en las condiciones de vida de los ciudadanos, se profundiza en la preparación y competencia de los profesionales del Trabajo Social, tanto los dedicados a la gestión como los que están en el nivel de intervención directa. Muchos voluntarios sociales recibieron formación y encontraron trabajos remunerados en el ámbito de la atención social. De ahí que autores, como Drucker, hayan escrito que la tradición del voluntariado fue aplastada por el Estado de bienestar (Druker, 1993, p. 175). Es significativo a este respecto lo que ocurre 
en el Reino Unido, cuando después de la Segunda Guerra Mundial, el Estado asume los servicios que prestaban instituciones privadas sin ánimo de lucro a través de organizaciones de personas voluntarias. Se planteó la polémica de que se ponía en peligro la existencia de dichas asociaciones del voluntariado. La polémica llegó hasta el propio Parlamento, a cuyas puertas se manifestaban, por lo que se creó una Comisión parlamentaria para su estudio. Dicha Comisión concluyó que, evidentemente, las organizaciones voluntarias disminuían con el desarrollo de los Estados de bienestar. También en España se suscitó en su momento una anécdota parecida. Ocurrió cuando fue creada por Moret la Comisión de Reformas Sociales. En el seno de dicha Comisión no faltaron voces que se alzaron en defensa de la atención social privada de carácter religioso (Malagón, 1999, p. 179). Se puede, pues, concluir, que a mayor desarrollo de bienestar por parte de los poderes públicos menor número de personas voluntarias dedicadas a menesteres asistenciales y mayor número de profesionales del Trabajo Social, así como se eleva la preparación académica de éstos. Este fenómeno se puede observar en el Gráfico 1.

En el caso español, encontramos este fenómeno de forma clara, y de hecho, en el periodo comprendido entre 1959-1975, se producen determinados acontecimientos que demuestran el desarrollo del Trabajo Social. Entre ellos, hay que señalar el papel jugado por Cáritas en la realización y estímulo de investigaciones sociológicas, y en la promoción de publicaciones como la revista Documentación Social. En 1959 se crea la Federación Española de Escuelas de la Iglesia de Servicio Social (FEISS) que jugará un gran papel en la formación profesional. Nace la Revista de Treball Social, en Barcelona, que constituyó (Brezmes, 2010, p. 264) un instrumento de primer orden para difundir reflexiones, compartir dificultades y experiencia, abordar viejos y nuevos planteamientos, etc. Se configuró como un eje esencial para la creación de la comunidad científica y profesional del Trabajo Social. Gracias a la revista se pudo empezar a construir y difundir el Trabajo Social español. En 1967 se crea la Escuela Oficial de Asistentes Sociales de Madrid. Es el primer centro público de España y el encargado de validar los títulos por medio de una prueba específica. También en 1967 se crea de Federación Española de Asistentes Sociales (FEDASS), que jugará un papel crucial en la historia del Trabajo Social en España. Sus actuaciones y reivindicaciones formarán los cimientos sobre los que se construye el edificio del Trabajo Social. En 1968 se celebra en Barcelona el Primer Congreso Estatal de Asistentes Sociales, siendo presidenta de FEDASS Benita Llopis (p. 266). En este primer congreso se aprueba el término «Trabajo Social» para determinar el campo de actividad propia del asistente social. En 1973 se crea en Barcelona el GITS (Grupo de Investigación, destinado a
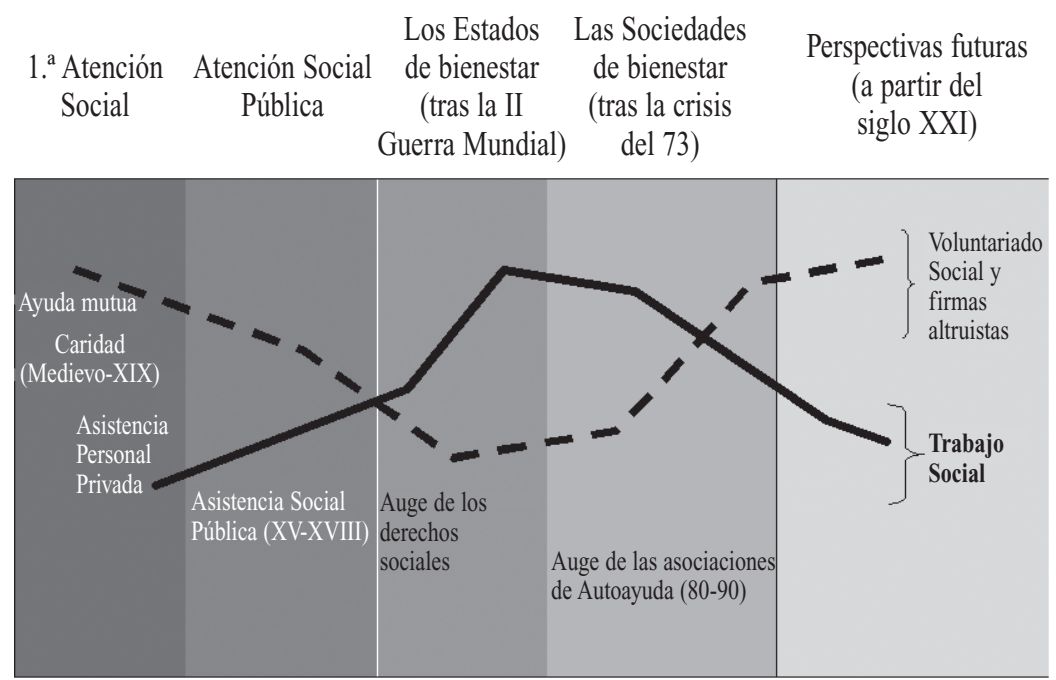

Gráfico 1. Importancia del Trabajo Social/Voluntariado Social. 
la formación permanente de asistentes sociales) que fue un referente para todo el colectivo.

A partir de 1975, y hasta los años 1980, destaca la celebración del III Congreso Profesional (1976), realizado en Sevilla, en el que se acepta el cambio de denominación de asistente social por el de trabajador o trabajadora social. En 1977 se crea el Cuerpo Nacional Especial de Asistentes Sociales, donde se produce el reconocimiento explícito y específico de la profesión por parte de la Administración. Para Brezmes (p. 278), será fundamental en este periodo la promulgación del Real Decreto $1850 / 1981$ de 20 de agosto en el que los estudios de asistente social se incorporaron a la universidad como Diplomatura de Trabajo Social. No será hasta 1990 cuando se cree el Área de conocimiento de Trabajo Social y Servicios Sociales. En este tiempo se observa cómo la importancia del ámbito universitario en la evolución del Trabajo Social español era cada vez mayor. Nace la revista Cuadernos de Trabajo Social de la Universidad Complutense, que marcará un camino que posteriormente seguirán otras universidades. Y por otra parte, la edición, por parte del Consejo General de Diplomados en Trabajo Social y Asistentes Sociales, de la Revista de Servicios Sociales y Política Social (1984). El dinamismo y la fortaleza del colectivo profesional, o al menos de su sector más activo, se muestra en la aparición de la Asociación Trabajo Social y Salud en 1986, con la publicación de una revista específica para esta área ( p. 283). A partir de estos años asistimos al desarrollo y la expansión disciplinar del Trabajo Social.

\section{Deconstrucción del Estado de bienestar}

Tomamos como punto de partida la existencia de un Estado Social, que como expone Hamzaoui (2005, pp. 31 y ss.), tendrá dos papeles fundamentales en lo social: de un lado, la corrección de disfunciones económicas, por el daño del crecimiento económico e industrial, y de otro, la consolidación de la cohesión social. Los problemas se presentarán cuando, a partir de la mundialización de la economía en las décadas siguientes y la territorialidad de las formas de acción social, asistamos a una desestabilización de la sociedad salarial (Castel, 1997), acompañada de tres fenómenos: degradación de la condición salarial; quiebra del sis- tema de protección social; fragilidad del vínculo social (Hamzaoui, 2005, p. 21). Además, estos fenómenos irán acompañados de: un aumento del paro; situaciones de desempleo más prolongados en el tiempo; y el desempleo como causa de exclusión social. (idem). Estos elementos tendrán influencia en las formas de ejercicio profesional como más adelante analizaremos a la luz de algunos datos de investigación.

Muy pronto el Estado de bienestar entra en crisis. Al inicio de la crisis se le suele poner la fecha de 1973, debido a las alzas de los precios del petróleo. Si no es la causa, que para muchos no lo es, sí es al menos la justificación para el comienzo del desmantelamiento del Estado Social. La idea-fuerza de que el Estado Social es insostenible es difundida con ahínco por los conservadores, que optan por la crítica frontal. En el campo teórico se desarrolla un enconado debate con autores, como Hayek, Milton Friedman y Buchanan, padres del neoliberalismo. Todos pensaban que la intervención del Estado debía reducirse al mínimo, achacando al Estado Social el origen de la inflación. Es el retorno de las ideas del liberalismo económico - neoliberalismo-y la vuelta a la situación pre-keynesiana, aunque lógicamente en otro contexto social y económico. Para otros, la crisis del Estado de bienestar no es económica, sino que son determinantes sociológicos y culturales las que la sustentan. (Rosanvallon, 1992, pp. 46-47). Lo cierto es que con el avance de las ideas neoliberales a partir de la década de los años ochenta del pasado siglo, junto con la innovación tecnológica y de la comunicación, se abandona el pleno empleo y se reduce el gasto social. Si unimos, como elemento simbólico, la caída del muro de Berlín de 1989, se puede considerar que estamos ante el comienzo de una nueva era caracterizada por un solo pensamiento dominante, puesto que el sistema comunista ha caído estrepitosamente. La nueva realidad mundial se presenta con una economía globalizada - con matices, por supuesto - sustentada en la concepción neoliberal del mundo. Se ha configurado un mundo unipolar con las conquistas sociales en crisis cuando no en franco retroceso. Estamos pues ante la situación denominada como «pensamiento único».

Será fundamental el proceso globalizado que se inicia por las finanzas y el comercio y 
termina afectando a las relaciones laborales e incluso personales. Las nuevas relaciones laborales marcadas por la globalización neoliberal influyen y son determinantes de las relaciones familiares. Las precariedades económica y familiar son un hecho constatable. Antes de la imposición del paradigma neoliberal, los trabajadores vivían bajo lo que Max Weber denominaba la «jaula de hierro», una estructura burocrática que racionalizaba el uso del tiempo, de forma y manera que daba seguridad al trabajador, permitiéndole hacer un proyecto de vida, ya que al final de su carrera laboral tenía también la seguridad de una pensión estatal. Esta seguridad laboral y, por ende, económica, le daba a su vida un sentido en tanto en cuanto que narración lineal (Sennett, 2000, p. 14). Hoy el trabajo seguro y estable dentro de una misma empresa constituye una pura utopía casi imposible de conseguir. El trabajador, si quiere trabajar, ha de someterse a la inestabilidad laboral, al cambio de puesto y de lugar de trabajo, así como a los contratos precarios. Como señala Sennett (2003), después de la Segunda Guerra Mundial el Estado de bienestar se dedicó a proponer la reducción de las desigualdades en aras a la cohesión social. Pero de este pasado estable se ha mutado a una inseguridad social. Hay incluso quienes consideran la desigualdad como un valor. Son tiempos que se mueven entre el individualismo y la reconstrucción de espacios comunitarios sin pretensiones de cambios globales (pp. 75-134).

El futuro del trabajo es la extensión de la precariedad. La desintegración del sistema de relaciones laborales nos aleja cada vez más del modelo clásico de empleo. Se ha pasado de una economía de empleo estable a un sistema neoliberal caracterizado por la precariedad, la movilidad y la flexibilidad, que unido a la privatización del sector público y a la desreglamentación del privado nos encuadra la realidad del presente. Ello ha dado lugar a una gran desigualdad global, como con rigurosidad nos ha expuesto el Premio Nobel de Economía Joseph Stiglitz en el libro El precio de la desigualdad: el 1 por ciento de la población tiene lo que el 99 por ciento necesita. En el que afirma que el 1 por ciento más alto dispone de las mejores casas, de la mejor educación, de los mejores médicos, y del mejor estilo de vida, pues hay una cosa que aparentemente el dinero no ha conseguido comprar: la constatación de que su destino está ligado a cómo vive el 99 por ciento restante (Stiglitz, 2012, p. 325). Así lo ponen de manifiesto varios estudios referidos a España, como el de Cáritas española titulado «De la coyuntura a la estructura: los efectos permanentes de la crisis») (Septiembre de 2012); el de la Red Europea de Lucha contra la Pobreza (Octubre de 2012); "Crisis y Fractura Social en Europa: causas y efectos en España», publicado por la Obra Social de la Caixa (2012). En síntesis, se ha pasado del fordismo al walmartismo, que es el modelo postfordista del siglo XXI. Wal- Mart es el mayor vendedor al por menor del mundo. Es considerada como una empresa-nación. El fordismo ayudó a crear una clase media obrera próspera gracias a unos salarios dignos y con un Estado que garantizaba una buena atención sanitaria, educativa y servicios sociales. Wal-Mart, camina en sentido contrario, es la empresa del siglo XXI, junto con un Estado Social en crisis y en retroceso. La competencia económica y el deseo desaforando de acumulación, así como la búsqueda de precios cada vez más bajos, traen consigo salarios más bajos, directivos autoritarios y persecución de los sindicalistas (Halimi, 2006, p. 20).

En el ámbito del Trabajo Social este fenómeno se ha manifestado con la reaparición con fuerza del Trabajo Social individualizado y con el relanzamiento de la atención social comunitaria. No es casual que en un mundo globalizado bajo el pensamiento neoliberal y con un decrecimiento de la acción social pública, de nuevo se vuelva a la atención de los problemas sociales en el ámbito comunitario; pero se hace no del término comunitario en el peor de los sentidos, dado que la comunidad tiene un gran poder simbólico y carece de connotaciones negativas. Se observa la comunidad con lentes románticas. Se pinta una imagen manifiestamente falsa de lo que es la vida corriente en el espacio local (Bauman, 2003, p. 140). El neoliberalismo crea - o más bien recrea- la ideología de lo local, de lo comunitario. En este pensamiento desaparece muy sutilmente el término Estado para ser sustituido por el de Sociedad. Es por lo que deja de hablarse de Estado de bienestar y en su lugar se habla de Sociedad del bienestar. Con este cambio de denominación se nos está indicando que es la Sociedad - no el Estado - la que tiene que pro- 


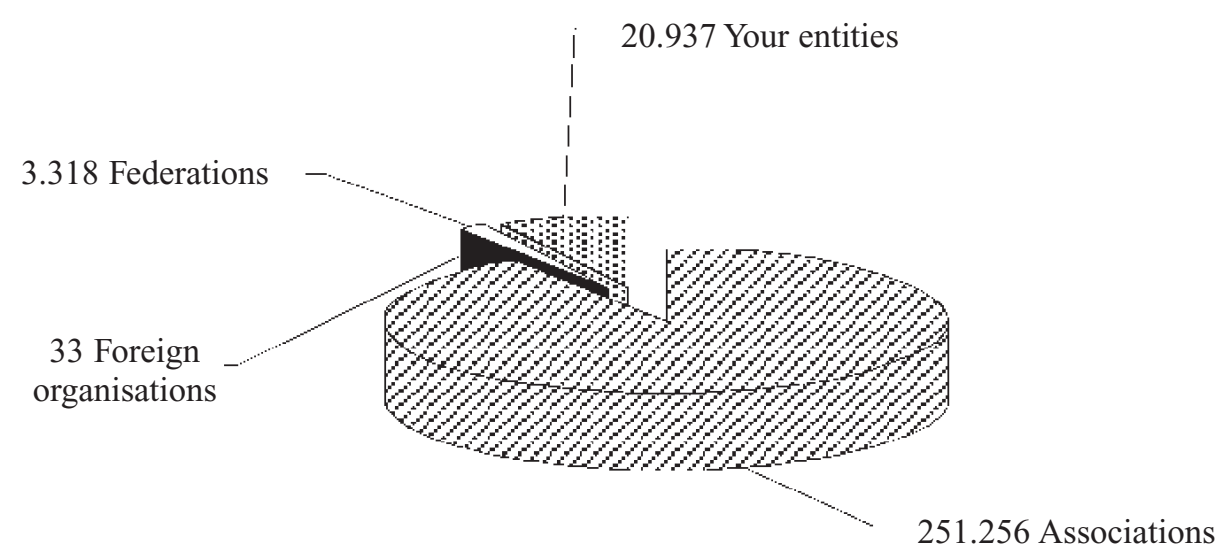

Gráfico 2. Entidades asociativas registradas en España (1980-2005).

Fuente: Malagón, Sarasola y Barrera, 2008, p. 147.

curarse su propio bienestar. La sociedad es un concepto abstracto, es un esencialismo. Realmente serán los individuos concretos los que tendrán que procurarse su propio bienestar.

Las políticas sociales europeas actuales se basan en devolver la atención social de las personas y grupos que necesitan de ayuda hacia las familias, los vecinos, las asociaciones voluntarias, etc. Se lanzan programas destinados al desarrollo de la atención comunitaria. Paralelamente a esta precarización de la atención social, se potencia por parte de los poderes públicos la proliferación de organizaciones de carácter voluntario que se hacen cargo de actuaciones destinadas a las prestaciones de servicios propios de los estados. Asistimos a la potenciación de esta Sociedad del bienestar por medio del apoyo al Tercer Sector y a costa de una cesión de funciones que hasta entonces eran responsabilidad y exclusividad de los estados: una privatización de lo social.

Se dan varias formas de privatización En el terreno industrial ha supuesto un cambio de propiedad, pero en los servicios públicos y sociales el efecto cambia. Hay que considerar la privatización en un sentido amplio, pues ésta no supone siempre un cambio de propiedad. Por ejemplo, en un centro sanitario el personal puede depender de una empresa privada, aunque los usuarios de la Seguridad Social no tengan que pagar por los servicios. También se avanza hacia la privatización por medio de la llamada externalización, consistente en la subcontratación por una empresa pública de servicios a empresas privadas. Con estas innovacio- nes privatizadoras se camina hacia situaciones anteriores al Estado de bienestar (Etxezarreta, 2010, pp. 14-16). Por otro lado, en no pocas ocasiones el altruismo de origen se convierte en grandes estructuras que captan cuantiosos recursos, recurriendo incluso a técnicas propagandísticas y de marketing que podemos comprobar constantemente. Ya en 2003 se publicó un informe sobre el Tercer Sector realizado por Pérez Díaz y López Novo que contabilizaba 15.000 ONG en España. Más recientemente podemos comprobar la profesionalización de las ONG en el estudio «Evolución de la profesionalización en las $\mathrm{ONG»} \mathrm{editado} \mathrm{por} \mathrm{la} \mathrm{Obra}$ Social de La Caixa (2011). En un estudio recientemente realizado en el contexto español (Malagón, Sarasola y Barrera, 2008), nos encontramos con datos que reflejan de manera muy clara una verdadera explosión de las organizaciones voluntarias y asociaciones diversas, a partir de los años 1980 en España, coincidiendo con una ralentización en las políticas sociales públicas. Sirva de ejemplo el Gráfico 2.

\section{La investigación}

Para ayudar a fundamentar los aspectos tratados en este artículo, nos basaremos en un estudio sobre la situación de los trabajadores sociales y su ejercicio profesional realizado a través de técnicas cuantitativas y cualitativas. Esta investigación buscaba analizar las formas en que los trabajadores sociales de Sevilla llevaban a cabo su ejerció profesional. Su objeto de análisis fue el perfil y características técnicas y profesionales del Trabajador social en Sevilla. Y 
para ello se marcó un ámbito de análisis en el que lo trabajadores sociales han cumplido las siguientes características: que se encontrasen en ejercicio profesional como trabajadores sociales en la provincia de Sevilla. Que se encontrasen colegiados. Para tener elementos de comparación también trabajadores sociales que no estuvieran colegiados y con más de 5 años de ejercicio profesional. Que fuesen tanto trabajadores por cuenta propia como por cuenta ajena. Que fuesen tanto de ámbitos públicos como privados. Que habiendo ejercido como trabajadores sociales se encontrasen jubilados. Sobre estos elementos se diseñó una metodología de investigación que planteaba diversas acciones agrupadas en las siguientes fases:

\section{a) Fase 1: preparación de la investigación}

Esta fase comprendió desde Julio de 2009 hasta marzo de 2010. Durante este tiempo, se procedió a la preparación de todos los elementos necesarios para el desarrollo de la investigación y por tanto, de la consecución de los objetivos. La fase se concretó en las siguientes acciones: definición de conceptos clave de la investigación; elaboración y diseño de los instrumentos de medición.; selección de colaboradores; y localización del 100 por ciento del universo.

\section{b) Fase 2: análisis del objeto}

Fue la fase más extensa de la investigación. En ella se llegó al campo de investigación y a partir del contacto con los sujetos de investigación, se obtuvo la información necesaria para la conclusión de la investigación. La fase se ejecutó entre Abril de 2010 y Enero de 2011. En esta fase se desplegaron en las siguientes acciones: realización cuestionarios y fichas; tabulación y análisis de los datos obtenidos en los cuestionarios y fichas anteriores; puesta en marcha de grupos de discusión; y análisis de datos de los grupos de discusión.

\section{c) Fase 3: conclusiones de la investigación}

En ella se establecieron las conclusiones de la investigación, ratificando o refutando las hipótesis planteadas, y se reflejaban en el informe final de la investigación. Esta fase comprendió desde Enero de 2011 hasta Junio de 2011. Se llevaron a cabo las acciones siguientes: establecimiento de las conclusiones finales de la investigación; redacción y elaboración del informe de investigación; presentación de los datos y difusión de los mismos.

Para el desarrollo nuestros planteamientos, nos centraremos exclusivamente en una parte de los datos cuantitativos extraídos del cuestionario. El instrumento en sí es un cuestionario muy estructurado y diseñado para la abstracción de información más concreta para la investigación. Su utilizó con una doble metodología: administrada a través de entrevistas cara a cara a través de 100 cuestionarios (véase Tabla 1), y para ampliar la cobertura se pasó el cuestionario por correo a sujetos con el mismo perfil (se confeccionaron un total de 56 cuestionarios). En total se trabajaron 156 cuestionarios (ídem).

Los principales elementos de validez y análisis del cuestionario quedan reflejados en las tablas 2 y 3 , y son los siguientes:

\section{Algunos resultados para el debate teórico}

En función del análisis a través de SPSS, podemos obtener algunos datos de especial importancia para este artículo.

El perfil del trabajador social en Sevilla: es mujer ( 84 por ciento de población femenina), con una edad de hasta 35 años (población muy joven: entorno al 60 por ciento de la muestra se sitúa entre el final de los estudios de Trabajo Social y los 35 años). Con un ejercicio de menos de 5 años (el 57 por ciento de la muestra lleva trabajando un periodo de tiempo corto en el lugar de trabajo actual; menos de 5 años. Tan sólo el 12 por ciento llevan trabajando en el lugar actual más de 20 años), que trabaja por cuenta ajena (escaso trabajo o iniciativa privada y empresarial: El 95 por ciento de la muestra encuestada trabaja por cuenta ajena), y con una escasa formación a la necesaria para el ejercicio profesional (sólo el 35 por ciento de la muestra encuestada confirma tener formación referente a un posgrado, experto y/o máster) y una práctica inexistencia de doctores.

Como elemento complementario cabe decir que un 15 por ciento de la muestra no ejerce como trabajador social, pero mayoritariamente ejercen en contextos sociales próximos al Trabajo Social, en situaciones de voluntariado social (no remunerado) o figuras profesionales de inferior remuneración, pero ejerciendo funciones equivalentes a la del trabajador social. 


\begin{tabular}{|c|c|c|c|c|}
\hline \multicolumn{3}{|c|}{ Entidades públicas encuestadas } & \multicolumn{2}{|c|}{ Entidades privadas encuestadas } \\
\hline \multicolumn{2}{|c|}{ Lugar } & N. ${ }^{\circ}$ encuestas & Ámbito & N. ${ }^{\circ}$ encuestas \\
\hline \multirow[t]{7}{*}{ Sevilla capital } & Casco antiguo & 2 & Personas mayores & 10 \\
\hline & Triana-Los Remedios & 2 & Infancia y juventud & 10 \\
\hline & Este & 2 & $\begin{array}{c}\text { Discapacidad } \\
\text { y dependencia }\end{array}$ & 10 \\
\hline & Sur & 2 & Mujer & 5 \\
\hline & Macarena & 2 & Inmigrantes & 5 \\
\hline & Nervión-San Pablo & 2 & Drogodependencias & 5 \\
\hline & & & Minorías étnicas & 5 \\
\hline \multirow{14}{*}{$\begin{array}{l}\text { Sevilla provincia } \\
+20.000\end{array}$} & Alcalá de Guadaira & 2 & & \\
\hline & Camas & 2 & & \\
\hline & Carmona & 2 & & \\
\hline & Coria del Río & 2 & & \\
\hline & Dos Hermanas & 2 & & \\
\hline & Écija & 2 & & \\
\hline & La Rinconada & 2 & & \\
\hline & Lebrija & 2 & & \\
\hline & Los Palacios & 2 & & \\
\hline & Mairena del Aljarafe & 2 & & \\
\hline & Morón de la Frontera & 2 & & \\
\hline & San Juan de Aznalfarache & 2 & & \\
\hline & Tomares & 2 & & \\
\hline & Utrera & 2 & & \\
\hline \multirow{3}{*}{$\begin{array}{l}\text { Sevilla provincia } \\
-\mathbf{2 0 . 0 0 0}\end{array}$} & & 10 & & \\
\hline & & TOTAL: 50 & & TOTAL: $\mathbf{5 0}$ \\
\hline & & & \multicolumn{2}{|c|}{ TOTAL 100} \\
\hline
\end{tabular}

Tabla 1. Distribución trabajo de campo de cuestionarios.

Fuente: Elaboración propia.

El declive del corporativismo: destaca una escasa vinculación con el Colegio Profesional, lo que muestra reflejos de un corporativismo en declive, con el que visualizamos la debilidad del colectivo. La población de trabajadores sociales colegiados no llega a ser el 25 por 


\begin{tabular}{|c|c|}
\hline Alfa de Crombach & N. $^{\text {o de elementos }}$ \\
\hline 0,764 & 101 \\
\hline
\end{tabular}

Tabla 2. Estadísticos de fiabilidad.

Fuente: Elaboración propia.

ciento de los trabajadores sociales de Sevilla.

Los cambios en su metodología: este cambio es de tipo generacional en las formas metodológicas de la profesión. Atendiendo a todo la población estudiada, los modelos de intervención más utilizados son: Sistémico ( 25 por ciento), Trabajo Social centrado en la tarea (12 por ciento) y casework, de diagnóstico y/o psicosocial (10 por ciento). Cruzando variables y analizando correlaciones, sacamos algunas informaciones interesantes. Los trabajadores sociales que llevan menos de 5 años se sienten más identificados con un modelo de trabajo social centrado en la resolución de problemas, en un 14,85 por ciento, el 13,5 por ciento se sienten más identificados con un modelo psicosocial, y el 28,35 por ciento se sienten más identificados con un modelo sistémico.

El contexto privado: atendiendo al contexto en el que el trabajador social realiza sus funciones, cabe destacar que el trabajador social de Sevilla proviene mayoritariamente del contexto público $\mathrm{y} / \mathrm{o}$ concertado ${ }^{1}$. Pese a ello, emerge un sector privado en trabajo social, como contexto de contratación; un 42,6 por ciento del total de trabajadores que han finalizado sus estudios (y hasta los 35 años) trabajan en entidades privadas sin ánimo de lucro. Y existe otra correlación significativa de un 15,62 por ciento del total de trabajadores sociales de edades comprendidas entre 26 y 35 años en las que, su entidad es privada con ánimo de lucro. La emergencia en el ámbito privado es básicamente sin ánimo de lucro y por cuenta ajena; el ámbito privado está aún por desarrollar ${ }^{2}$, en el tipo de «con ánimo de lucro».

El Trabajo Social territorializado: uno de los elementos más destacados del estudio es la confirmación de las teorías expuestas por Hamzaoui (2005) sobre el Trabajo Social terri-

\begin{tabular}{|c|c|c|c|}
\hline Media & Varianza & $\begin{array}{c}\text { Desviación } \\
\text { típica }\end{array}$ & $\begin{array}{c}\text { N. }{ }^{\mathbf{o}} \text { de } \\
\text { elementos }\end{array}$ \\
\hline 237,23 & 573,613 & 23,950 & 101 \\
\hline
\end{tabular}

Tabla 3. Estadísticos de la escala.

Fuente: Elaboración propia.

torializado. En este sentido encontramos como punto de partida que una amplia mayoría de la muestra encuestada (48 por ciento) desarrolla su actuación profesional en ámbitos municipales, seguidos de los que lo hacen en ámbitos provinciales ( 27 por ciento) y ámbitos autonómicos (18 por ciento). Un pequeños porcentaje (7 por ciento), realizan su actuación en ámbitos estatales ( 5 por ciento) e internacionales ( 2 por ciento). A partir de este dato podemos concretar que el tipo de Trabajo Social de los trabajadores social de Sevilla es básicamente «territorializado». A este respecto el 66 por ciento de la muestra encuestada enmarcan su intervención profesional según políticas sociales y autonómicas y económicas locales. El 24 por ciento lo hacen según políticas sociales y económicas nacionales e internacionales, mientras que el 10 por ciento restante reconoce desconocer estas directrices. Esto nos confirma elementos ya trabajados por Hamazaoui cuando hablaba del «Trabajo Social Territorializado». En cambio el profesional del Trabajo Social (90 por ciento de la muestra) considera que la intervención del trabajador o trabajadora social se encuentra condicionada o relacionada con las políticas económicas que superan el marco local y nacional. Pero a un tiempo desconoce los lazos que su ejercicio profesional tiene con los niveles globales. El 58 por ciento de la muestra encuestada considera que la intervención del trabajador o trabajadora social se encuentra influenciada por decisiones y situaciones internacionales, mientras que un 30 por ciento opina que esta intervención no guarda relación con situaciones y decisiones internacionales. Son pocos los trabajadores sociales que toman conciencia de esto. Paralela a la idea de territorialidad del Trabajo Social es

1 La mayor parte de la muestra encuestada (47 por ciento) pertenecen a entidades de la Administración Pública, seguidos de los profesionales que pertenecen a entidades privadas sin ánimo de lucro (30 por ciento).

2 Se correlaciona con algunas de las actividades menos realizadas por trabajadores sociales: captación de fondos (61 por ciento) y peritaje (56 por ciento). 
el dato que nos confirma que una amplia mayoría de la muestra encuestada, el 78 por ciento considera que existen importantes diferencias en el contexto nacional respecto a los recursos con los que se cuenta para hacer trabajo social, y que esto influye en las formas de hacer Trabajo Social.

Los hándicaps de la profesión: las principales limitaciones en el ejercicio profesional detectadas serían: el excesivo volumen de trabajo, el 91 por ciento; la insuficiencia de plantilla (80 por ciento): las condiciones de trabajo inapropiadas el 60 por ciento; los riesgos para la integridad física y psicológica, el 63 por ciento. El 60,77 por ciento del total de trabajadores sociales que ejercen la profesión, están expuestos a riesgos para su integridad física o psicológica derivada de su actividad laboral. De la muestra, el 74 por ciento del total de los trabajadores sociales que están más expuestos a riesgos para su integridad física o psicológica derivados de su actividad laboral, desempeñan su labor en el ámbito municipal y provincial. Los más expuestos a riesgos son los trabajadores sociales de los ámbitos locales. Por otro lado, podemos observar que el 37,26 por ciento del total de trabajadores sociales que están expuestos a riesgos para su integridad física o psicológica pertenecen a los Servicios Sociales comunitarios. Con el grupo poblacional con el que se producen más riesgos es con menores, el 16,56 por ciento; le sigue en el contexto laboral de salud, con el 13,8 por ciento. El mejor de los contextos para el ejercicio del Trabajo Social por tener menores riesgos personales es el de mayores (nos indican los trabajadores sociales que el de menor riesgo, el 13 por ciento). Los problemas de conciliación de la vida laboral y familiar representan el 78 por ciento. Otros elementos que afectan en menor medida son: la realización de tareas no apropiadas, el 54 por ciento; las malas relaciones con compañeros o superiores, el 59 por ciento; la remuneración escasa, el 40 por ciento; el desconocimiento de la política social, el 55 por ciento; el desconocimiento de la legislación, el 58 por ciento; el desconocimiento de nuevas formas de intervención, el 58 por ciento; y el intrusismo profesional, el 58 por ciento.

La precariedad laboral: otro de los elementos en los que el estudio puede suscitar debate es precisamente el de la detección de una ten- dencia a la precariedad laboral del colectivo de trabajadores sociales. Precariedad laboral de los egresados en Trabajo Social: en total en 5 años se han realizado 3.400 contratos de trabajo de los cuales 3.105 han sido temporales, es decir, el 92 por ciento. Los indefinidos suman 295 contratos, siendo solo el 8 por ciento. Además, encontramos que hay poca estabilidad en el puesto de trabajo. El 88,2 por ciento del total de los trabajadores sociales lleva trabajando en este lugar menos de 5 años.

Las transformaciones paradigmáticas: se detecta un alejamiento del paradigma conflictual según los modelos planteados por Howe (1999). Dentro de las actividades menos realizadas por el trabajador social destacan: la creación de nuevos recursos, el 42 por ciento, y las tareas de organización, gestión y participación comunitaria, el 38 por ciento; ambas son ejes fundamentales de la forma de trabajo según este paradigma. Al tiempo se produce un énfasis ya mencionado anteriormente del funcionalismo. El trabajador social se halla alejado de la captación y creación de recursos que lo recluyen a figuras de gestión de recursos y no de creación de los mismos (funcionalismo). Este alejamiento de la figura del trabajador social comunitario por excelencia, le aparta del trabajo con la comunidad y desde la comunidad (verifica las tesis también apuntadas por Hamzaoui, 2005). Se trata por lo tanto de una ruptura con los paradigmas conflictual y hermenéutico.

\section{Los cambios en el Trabajo Social}

Vinculando los datos obtenidos con la investigación, y las distintas aportaciones teóricas y analíticas, queremos destacar las siguientes conclusiones.

En primer lugar, encontramos una relación de paralelo deterioro entre la deconstrucción de las formas ortodoxas del Estado de bienestar y las nuevas formas del ejercicio profesional del Trabajo Social. Estas se concretan en características que a niveles teóricos hemos visto describir a Castel (1997) y Hamzaoui (2005): un aumento de la precariedad laboral en el colectivo de trabajadores sociales; aumento de la inestabilidad y antigüedad en el puesto de trabajo; insuficiencia de plantilla para el correcto ejercicio de las funciones profesionales; problemas de conciliación laboral y 
familiar; detección de escasa remuneración para el colectivo de trabajadores sociales; sobrecarga y excesivo volumen de trabajo; denuncia de un importante intrusismo profesional; $y$ aumento de la atención social de carácter privado (según los datos expuestos anteriormente, básicamente desde el Tercer sector con ánimo de lucro, y especialmente en las últimas generaciones de egresados), y disminución de la pública, o sustitución de esta última por contextos privados con «concierto público».

En segundo lugar, estos cambios contextuales han producido también cambios y reajustes en la formas de ejercicio profesional y, en concreto, reajustes en la metodología del Trabajo Social. En cualquier caso se produce un auge del funcionalismo en términos paradigmáticos, que resulta un paradigma mucho más cómodo en las líneas del neoliberalismo, al tiempo que los datos nos muestran un alejamiento y desplazamiento casi total del paradigma conflictual y sus modelos de intervención, en tiempos pasados más extendido e incómodo para las corrientes ideológicas dominantes.

En tercer lugar, hemos de hacer una reflexión en torno a la figura de los voluntarios sociales. Desde el inicio del artículo venimos trabajando esta idea que tiene relación con las características actuales de deconstrucción del Estado de bienestar y las transformaciones en nuestra profesión. Tal y como se argumentó al inicio del presente artículo, el voluntariado social y el Trabajo Social llevan caminos por los que el aumento de uno supone la disminución del otro. Es decir, a mayor desarrollo del Estado de bienestar, mayor desarrollo de la profesión del Trabajo Social y menor necesidad del voluntariado social. Con la deconstrucción del Estado de bienestar, la emergencia de las «Sociedades de bienestar», se pasa a una defensa y desarrollo del Tercer Sector y especialmente de las funciones socio-asistenciales del voluntariado, que en muchas facetas pretenden prescindir del trabajador social. En la tendencia señalada a partir de los datos obtenidos, se corrobora este argumento, en concreto en dos indicadores: el auge de las entidades de voluntariado social al amparo del desarrollo legislativo, y que el propio estudio ha detectado en ese 15 por ciento de la muestra que no ejerce como trabajador social, pero realiza las funciones del mismo como voluntariado social, es decir: encontramos trabajadores sociales que realizan sus actividades profesionales como voluntarios sociales, sin retribución.

En cuarto lugar, y en la línea argumental que venimos desarrollando, detectamos en el estudio un acentuado declive del corporativismo, teniendo como eje fundamental el dato de la colegiatura. El estudio nos dice que el dato de colegiación no llega a ser el 25 por ciento de los trabajadores sociales de la muestra. Si este dato lo cruzamos con la población de egresados, los porcentajes caen por debajo del 10 por ciento, y en algunas promociones de egresados no llegaría al 5 por ciento. Este dato, de debilidad representativa y legitimidad del colectivo de trabajadores sociales, tiene su analogía social con otros colectivos sociales, aquellos representativos y de reivindicación profesional o social, como el caso del sindicalismo, quienes tampoco viven momentos de auge.

En quinto lugar, y cruzando las anteriores conclusiones con otros datos del estudio, comprobamos que se da una importante correlación del contexto de la profesión con los elementos anteriormente analizados como «trabajo social territorializado». La causas de los problemas son globales, sin embargo la atención social se privatiza, individualiza y pierde se profesionalidad con la irrupción del voluntariado en gestión de los servicios sociales. Nos encontramos ante una paradoja. Por una parte vivimos en una sociedad globalizada, caracterizada por el predominio de las ideas de modernidad, racionalidad y progreso; sin embargo, decimos que se da una situación paradójica porque en la acción social hay una vuelta a lo comunitario, a la familia, a los vecinos, a los voluntarios en definitiva. A pesar de todo, no hay más que una contradicción aparente, porque lo que realmente se pretende es devolver a la esfera privada la prestación de los servicios sociales, dado que en la óptica dominante es más barato. No hay, pues, contradicción entre los servicios sociales que emergen y las ideas neoliberales que imperan. Autores como Payne, Adams y Dominelli (2005), llegan incluso a explicar que el Trabajo Social dentro del contexto de lo público es un trabajo social limitado y oprimido, entendiendo mejor para la profesión los ámbitos privados. Argumentos como éstos vienen a justificar los cambios últimos en las perspectivas profesionales en la línea del 
abandono de los espacios públicos, y en la consolidación de los espacios privados, o incluso pseudo-profesionales, de los voluntariados sociales.

Como podemos observar, el Trabajo Social se encuentra ante importantes retos que la realidad de su contexto le demanda. No es algo nuevo, el Trabajo Social a lo largo de su historia se ha ido adaptando a su entorno. Tenemos la impresión de que en Trabajo Social se está cumpliendo el mito del «eterno retorno», dado que es una profesión que nace fundamentalmente por la reconversión del voluntariado en una actividad profesional, y que la situación actual está proponiendo la vuelta a sus orígenes. Evidentemente la historia no se repite, pero a veces los fenómenos sociales se parecen mucho, aunque los contextos sean otros.

\section{Referencias bibliográficas}

Adams, R., Dominelli, L. y Payne, M. (2005). Social Work Futures. Crossing boundaries, transforming practice. Nueva York: Palgrave Macmillan.

Bauman, Z. (2003). Comunidad. Madrid: Siglo XXI.

Brezmes, M. (2010). Antecedentes, inicio y evolución del Trabajo Social en España (Finales del s. XIX-1975). En A. Gutiérrez Resa (ed.), Orígenes y desarrollo del Trabajo Social (pp.251272). Madrid: Ediciones Académicas S.A.

Castel, R. (1997). Las metamorfosis de la cuestión social. Barcelona: Paidós.

Droz, J. (1984). Historia general del socialismo. Barcelona: Destino.

Drucker, P (1993). La sociedad postcapitalista. Barcelona: Apóstrofe.

Esping-Andersen, G. (1993). Los tres mundos del Estado del Bienestar. Valencia: Alfons i Magnánim.

Etxezarreta, M. (2010). Qué pensiones, qué futuro. Barcelona: Icaria.

Giner, S. (1983). Comunidades sociales adultas (grupos sociales intermedios). Madrid: Mezquita.

Halimi, S. (2006). Wal-Mart al asalto del mundo. En Revista Le monde diplomatique, 123.

Hamzaoui, M. (2005). Trabajo Social Territorializado. Las transformaciones de la acción pública en la intervención social. Valencia: NAU Libres.

Howe, D. (1999). Dando sentido a la práctica. Una introducción a la teoría del trabajo social. Granada: Maristán.

Johnson, N. (1990). El Estado de Bienestar en transición. Madrid: Ministerio de Trabajo y Seguridad Social.

Keynes, M. (1981). Teoría general de la ocupación, el interés y el dinero. México: F.C.E.

Malagón, J.L. (1999). Fundamentos del Trabajo Social Comunitario. Sevilla: Aconcagua.

Malagón, J.L. Sarasola, J.L. y Barrera, E. (2008). Social Work: Progress or backward movement? En V. Fortunato, G.J. Friesenhahn y E. Kantowicz (eds.), Social Work in Restructurated European Welfare Systems (pp. 139-150). Roma: Carocci Editore.

Pérez Díaz, V. y López Novo, J.P. (2003). El Tercer Sector Social en España. Madrid: Ministerio de Asuntos Sociales.

Rosanvallon, P. (1992). La crisis del Estado providencia. Madrid: Civitas.

Sennett, R. (2000). La corrosión del carácter. Las consecuencias personales del trabajo en el nuevo capitalismo. Barcelona: Anagrama.

Sennett, R (2003): El respeto. Barcelona: Anagrama.

Stiglitz, J. (2012). El precio de la desigualdad. Madrid: Taurus. 